\title{
Respiratory Function Monitoring in Preterm Infants with Spontaneous Breathing or Apnoea during Sustained Inflations after Birth
}

\author{
Schwaberger, B $^{1}$; Schober, L1; Schmölzer, GM²; Baik-Schneditz, N¹; Pichler, $\mathrm{G}^{1}$; Urlesberger, $\mathrm{B}^{1}$ \\ ${ }^{1}$ Division of Neonatology, Department of Pediatrics, Medical University of Graz, Austria, \\ ${ }^{2}$ Neonatal Research Unit, Royal Alexandra Hospital, Edmonton, Canada
}

\section{BACKGROUND AND AIM:}

Sustained inflations (SI) during postnatal stabilisation of preterm infants may promote alveolar recruitment and improve gas exchange.

The aim of the present study was to investigate whether spontaneous breathing during $\mathrm{SI}$ influences alveolar recruitment and gas exchange during postnatal stabilisation.

\section{METHODS:}

For this post-hoc analysis respiratory function parameters of preterm infants $\geq 23+0$ and $<34+0$ weeks of gestation enrolled into two randomized controlled trials in Graz (Austria) and Edmonton (Canada) were analysed.

The initial respiratory management consisted of 1 to 3 $\mathrm{SI}$ followed by either positive pressure ventilation or continuous positive airway pressure applied by TPiece devices via face mask. Respiratory function monitoring was performed by using Florian Respiratory Function Monitor (Acutronic) in Graz and Respironics NM3 (Philips Healthcare) in Edmonton.

Group differences of the first detected end-tidal $\mathrm{CO}_{2}$ $\left(\mathrm{ETCO}_{2}\right)$, expiratory $\left(\mathrm{V}_{\mathrm{Te}}\right)$ and inspiratory tidal volumes $\left(\mathrm{V}_{\mathrm{T}_{\mathrm{i}}}\right)$ during and one minute after the initial $\mathrm{SI}$ in infants with and without spontaneous breathing during $\mathrm{SI}$ assessed via flow wave forms were evaluated.

\section{RESULTS:}

A total of 27 preterm infants with a mean gestational age of 28 weeks (range $23-32$ ) and a mean birth weight of $1209 \mathrm{~g}( \pm 455)$ were included. Demographics were similar between groups. The mean duration of the initial SI was $21.1 \mathrm{sec}( \pm 7.2)$, the mean peak inspiratory pressure was $33.0 \mathrm{cmH}_{2} \mathrm{O}( \pm 3.3)$ and the mean plateau pressure was $25.2 \mathrm{cmH}_{2} \mathrm{O}( \pm 1.4)$.

\begin{tabular}{|c|c|c|c|}
\hline & $\begin{array}{c}\text { Spontaneous } \\
\text { breathing }(n=17)\end{array}$ & $\begin{array}{l}\text { Apnoea } \\
(n=10)\end{array}$ & $\begin{array}{c}\text { P-value } \\
(* p<0.05)\end{array}$ \\
\hline$V_{T e}$ at the end of the $\mathrm{SI}(\mathrm{ml} / \mathrm{kg})$, median (IQR) & $3.9(8.3)$ & $3.6(6.5)$ & .537 \\
\hline Max. ETCO ${ }_{2}$ after SI-expiration ( $\mathrm{mmHg}$ ), median (IQR) & $11.8(19.0)$ & $5.2(16.5)$ & .243 \\
\hline Time until first detectable $\mathrm{ETCO}_{2}(\mathrm{~s})$, median (IQR) & $6.2(9.1)$ & $20.3(21.5)$ & $.018^{*}$ \\
\hline Time until $\mathrm{ETCO}_{2}>20 \mathrm{mmHg}(\mathrm{s})$, median (IQR) & $23.1(9.6)$ & $111.0(163.2)$ & $.023^{*}$ \\
\hline
\end{tabular}

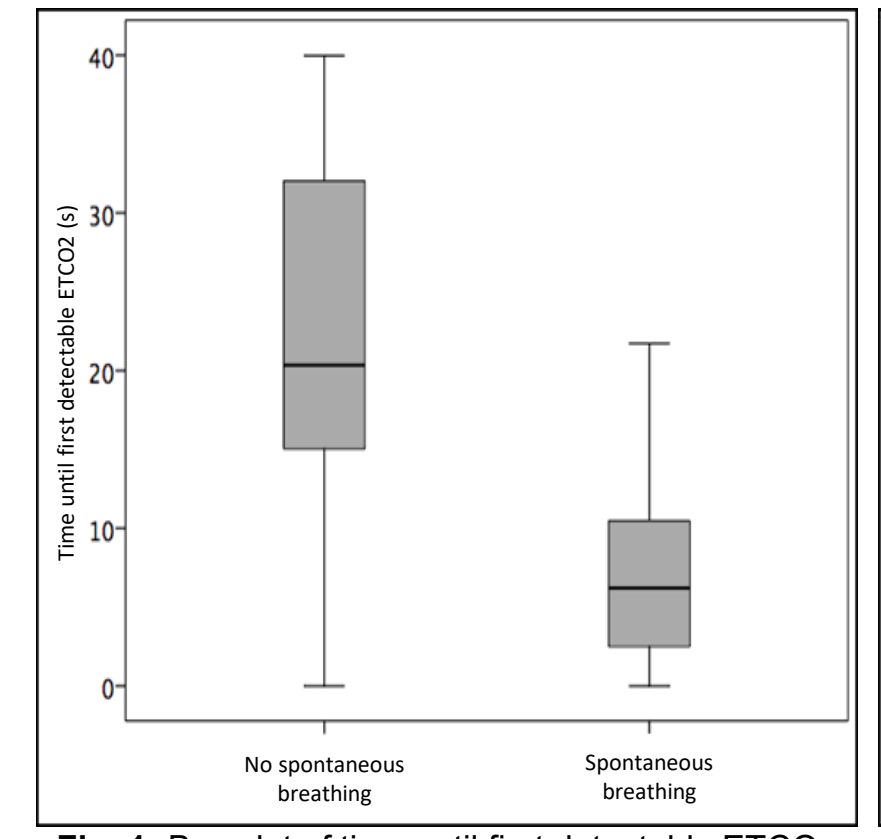

Fig. 1: Box plot of time until first detectable $\mathrm{ETCO}_{2}$ in infants with and without spontaneous breathing
There were no significant differences between infants with and without spontaneous breathing during SI when either the cumulative $\mathrm{V}_{\mathrm{Ti}}$ and $\mathrm{V}_{\mathrm{Te}}$ during the first $\mathrm{SI}$ or the $V_{T_{\mathrm{e}}}$ at the end of the first $\mathrm{Sl}$, or the $\mathrm{V}_{\mathrm{Ti}}$ and $V_{T e}$ in the first minute after $\mathrm{SI}$ were compared suggesting similar tidal volume delivery.

Fig. 4: Characteristic example of respiratory function parameters in an infant with spontaneous breathing during the initial SI

\section{CONCLUSION:}

Preterm infants who spontaneously breathe during SI have earlier $\mathrm{ETCO}_{2}$ compared to apnoeic infants suggesting improved alveolar recruitment and gas exchange. No significant differences in mean tidal volumes during and after SI were observed between both groups. 